\title{
Who has the largest share in automotive (car) industry of Pakistan?
}

\author{
Ai Huu Tran ${ }^{1}$, Muhammad Imtiaz Subhani ${ }^{2}$, and Denis Ushakov ${ }^{3, *}$ \\ ${ }^{1}$ Van Hien University, Dien Bien Phurong 1, Quan 3, Hồ Chí Minh 700000, Vietnam \\ ${ }^{2}$ ILMA University, Main Ibrahim Hyderi Road, Korangi Creek, Karachi, Pakistan \\ ${ }^{3}$ Suan Sunandha Rajabhat University, 1 U-Thong Nok rd., Dusit, Bangkok, 10300, Thailand
}

\begin{abstract}
This research aims to better comprehend \& dissect the supply $\&$ demand in automotive industry of Pakistan. The primary objective of this study is to delve into casing-works which empowers us to better understand the biggest piece of the overall automotive (car) industry of Pakistan by utilizing interest $\&$ expense parameters of automotive items in business sector. The research aims to determine market shares of automotive (car) brands in Pakistani automotive industry. Finding confirms that in Pakistan in automotive or automobile (cars) industry, the Suzuki brand is enjoying the highest market share among the selected/ outlined brands and leading the industry with $29 \%$ of market shares. Toyota is enjoying $26 \%$ market shares while Honda brand is the third most winning brands in automotive industry in Pakistan with $25 \%$ market shares. Further, Nissan, Kia and Daihatsu have 10\%, 6\% and 4\% market shares respectively for the years 2000 to 2019. In developing countries like Pakistan individuals have relatively lower wages, thus a vehicle-purchase decision requires more due-diligence, whereby the accessibility of car-parts in neighborhood markets, how pricy the car parts are, \& the resale estimation of brand, are the primary decision-marking factors. The highest market shares which is being enjoyed by Suzuki brand confirms that people of Pakistan buy Suzuki brand mostly due to the above mentioned factors. Therefore automotive businesses need not only focus upon bringing vehicles into the Pakistani market, but also need to focus upon rating high in the purchase decision-making factors as that of car-parts availability, credit/installment payments, and a worth-while resale price.
\end{abstract}

\section{Introduction}

The automotive industry of Pakistan is performing great since the past couple of decades, whereby individuals have been able to get marked vehicles at low costs although the primary purchase inclination of customers is towards the imported used-vehicles. The National Engines Ltd. were the pioneers of automotive industry in Pakistan, as they were the first ones to offer of trucks \& heavy transportation vehicles, and with the progression of time came to infuse automobiles in their portfolio.

\footnotetext{
${ }^{*}$ Corresponding author: denis.us@ssru.ac.th
} 
Administrative policies of 1990s encouraged financial specialists to direct resources into the auto-industry of Pakistan, bringing together huge players like Suzuki, Toyota and Honda; which later came to develop cooperation under the umbrella of Pakistan Automotive Manufacturers Association (PAMA).

Automotive industry in Pakistan offers business and employment to over 200,000 people. Amongst the automobiles, the $1300 \mathrm{cc}$ Toyota Corolla takes up a huge chunk of the overall industry, followed by Honda City. Furthermore, Suzuki occupies the most of the under $1000 \mathrm{cc}$ automobile market, with cars like Suzuki Khyber, Cultus, and Alto. The company has additionally been gaining significant market of under $800 \mathrm{cc}$ automobiles, by offering automobiles like Suzuki Mehran \& Bolan. In the motor-bikes sector however Honda remains as the market leader, while presently imported bikes from China are likewise gaining more and more of the sector.

The automotive industry can be classified into the following: light transport vehicles (LTVs), bikes, trucks, tractors, car-parts makers, \& merchant industry. The aggregate capital-investments in this industry reach up to Rs. 92 billion, while both directly and indirectly employing up to five million individuals. The industry produces up to 200,000 motor-vehicles \& up to 1.8 million bikes per annum. The industry is such a big part of the Pakistani economy that it makes up around 5\% of the country's gross domestic product.

The nation-wide situation of peace along-with the lack of an effective administration is however dragging down growth-levels of this industrial sector. Legislature, in Pakistan, has not been able to encourage investments in this sector and has allowed permeation of used imported autos which further harms the industry. Only recently has the legislature overhauled import arrangements, now permitting just about three year old vehicles rather than the previously set allowance of more than five year old vehicles; this has given a boost to the local manufacturing and assembling industry, revitalizing the entire sector. Furthermore, many other industries rely heavily on the automobile industry, whereby the biggest dependent industry is that of the auto-part industry, which yearly reaches up to Rs. 130 million worth of trade.

Furthermore, globalization has greatly influenced Pakistan's economy, whereby manufacturers from abroad and investors from within the country have been extensively working together, with such collaborations dominating the local markets. Due to globalization the worldwide economy has come to not limit itself with geographical limits anymore, forever changing the dynamics of aggressiveness in business. The world has shriveled \& become more competitive whereby anybody can enter the fields of rivalry.

Toyota has been ranked as the third most successful auto manufacturer in world and the number one auto organization in Japan in the year 2000. In the late 1990s, Toyota delivered just about five million units every year and held up to $10 \%$ share of the total worldwide automobile market. In the historical backdrop of auto assembling the organization has achieved great feats, forever changing operations management. The Toyota achievement \& success demonstrates Japan's stunning resurrection after the Second World War. Kiichiro Toyoda had previously visited the US where he looked at the various generations of autoplants amidst the 1933. Toyoda's first model car came out in May 1935 in Japan. Although Toyota was a mere start-up, yet the U.S. predominance in the worldwide auto-industry did not debilitate Toyoda.

This study aims to determine as to which car-manufacturer holds most of the marketshare and influence in the country of Pakistan. Presumably the likely winning candidates are that of Suzuki and Toyota, yet Hyundai, Daihatsu, Honda, Kia, and Nissan have been doing just as great in Pakistan, if not more. This study thus determines with the help of data the effective rankings of the mentioned car manufacturers of Pakistan. 


\section{Literature review}

Altinkaya investigated into the impact of globalization on the automobile industry of Pakistan during the American financial crisis of 2008, the automobile industry worldwide took a great hit all across the planet [1]. As has been integrated by the framework of Breton Woods Agreement, variations in the American economy ripple world-wide, which also affects Pakistan and its automobile industry. This ripple effect has been identified as they key feature of globalization. American finance is highly credit dependent, whereby economic stimuli often lead to risky investments which when dissolve lead to an overall increased volatility of local markets.

The global automobile industry is amongst the largest of businesses sectors, with sales reaching up to 65 million units as recorded for the fiscal year of 2012.In nations, with specialize in car manufacturing, like Japan, US, Germany, \& South Korea, the automobile industry is an integral part of the society. Furthermore, countries like China, India, and Malaysia have worked in the past several decades to develop their automobile industry, which they view as essentially a symbol of economic growth, process and national standing.

A huge inflow of imported vehicles (both used \& new) was demonstrated to not have an adverse impact on the Japanese car industry. Nevertheless, the American Motors Corporation (AMC) has been against the import relaxations and has long contended for increased barriers. AMC argues that government ought to back the local businesses as opposed to bringing about foreign competition for them [2,3].

In the context of Pakistan, Honda firstly dominated the market with a 47 percent share of the overall industry by the year 2006; however, the company's share subsequently dropped to 30 percent in the year 2007. The company experienced growth in the year 2008 , recording a market share of $35 \%$ during the year.

However, with the turn of events Suzuki now holds a 56 percent market-share, which is a total five times higher than that of Honda as presently. Suzuki has during the past years strategically positioned itself to focus on the manufacturing efficiencies and optimization in order to effectively cater to the market demands. The company specializes in small hatchback cars (of $800 \mathrm{cc}$ to $1000 \mathrm{cc}$ ) which target the white-collar service while Honda remains focused on capturing the rather smaller markets of sedans and coupe (Civic and Accord respectively) while failing to cash-in on the massive market of affordable hatchbacks [4].

McFadden, et al. (1977) utilization reenactment to produced total expectations from smaller scale parameter gauged [5]. [6] permits costs to be connected with a direct unsettling influence in a balance evaluating mathematical statement yet does not expressly demonstrate the connection between costs \& surreptitiously attributes. Since depended on basically total information, there are two proposals for improving any accuracy issues that may emerge. To begin with, demonstrate to utilize generally accessible information on the appropriation of purchaser attributes to gather business level data. Second, utilize current results to register a productive instrumental variables estimator for our framework.

This was exceptionally rich system which has not totally abused. Utilized a solid supposition on the orthogonality of watched $\&$ in secret item attributes. Despite the fact that this is a characteristic beginning spot, it is suspicions that can be loose in future work.

This structure is sufficiently rich to consolidate nontrivial elements \& indigenize the dissemination of item properties. These primitives allots qualities to diverse conceivable blends of item, attributes as a component of shopper attributes, an expense capacity which decides the creation expense connected with distinctive mixes of item attributes, an appropriation of purchaser qualities \& a dispersion of item qualities. The main compares to conventional arrangement examination, while the second gives a translation of the 
progressions that have happened in the business. It is anything but difficult to rundown approach addresses that our appraisals may be utilized to help examine. These include: exchange arrangement, merger strategy, natural approach \& the development of value records.

[7] founded the hobby adaptability's expect a key part in each of these issues \& thus the schedules made. Of course, most of the models, including our, are confined in that they give simply a "prohibitive" examination of issues.

That is, to do game plan examination, and needed to bother somewhat number of parameters \& process new congruity dependent upon substitute primitives of the model staying unaltered [8].

Really a significant part of the time these "primitives" had change in light of a modification in methodology or environment. On the other hand, by 1976 new little fuel proficient models presented \& our forecasts, in light of settled qualities, got to be extraordinarily more terrible \& decayed further over the long run. Global rivalry has expanded in recent decades. As indicated by [9] since the nature of products is dictated by clients consequently they are the main component that can make Rivalry between associations. Further, this makes production lines to have more concentrate on quality.

These days, rivalry has ended up about the information of clients needs \& needs. [9] noticed that associations need to make new administration in light of aggregate quality administration. [10,11] communicated quality organization is a champion amongst the most basic considers any affiliation. Productive endeavors fathom the common effect of customer \& quality can have on business.

Numerous aggressive organizations continually were enhanced their quality gauges [10, 12]. In the event that the organization does not center the quality, brings about client disappointment. Such a methodology brings about lost clients \& give open doors for opponents to catch advantage of this. Subsequently, giving careful consideration to clients made quality a need. As [10] expressed "It means meeting client desires by including everybody in the association through a coordinated exertion.

This exertion is known as Aggregate Quality Administration (TQM). As per [13] TQM is consider that persistent change all associations by means of enhances quality $\&$ a comprehensive methodology. TQM is an important device for every association in a focused domain. TQM is recognized as a cause of advancement, upper hand, \& hierarchical society [14]. Subsequently, if an organization served low quality in association brings about client disappointment.

As per [14] execution estimation can be considered as a key. One, auto industry is the 2nd best industry in Iran. Second, it participate huge duty to the Total national output of Iran. Third, this division particularly uses $2.3 \%$ workforce of the country. Fourth, this industry is looking to fare its items in worldwide markets.

Because of expanding clients desire, merciless rivalry, turbulent business environment, \& expanding requests Iranian Car Industry must consider TQM, which is a major issue confronted by this part. ID of components influencing congruity of agreeable electronic inventory network connections. The fast advancement of the web \& e-exchange has change the business procedures, energized across over supply chains.

[15] founded that the good use of information has impact on execution of generation system, in regards to total expense \& organization level. Auto associations have utilized advancement \& electronic instruments to organize stock system information structures. The pivotal reports \& data exchange association of these dealings are proposed to exchange information through the web.

Rapidly, suppliers of rough material \& parts can offer things to different motor associations all together. Motor associations don't grasp the same information structures, or accept a primary position in the creation system. Suppliers make diverse electronic 
information structures to manage the appeals of motor associations, clearly achieving an expanded weight in regards to wander cost \& structure upkeep. In this situation Suppliers are likely focused on that they may lose a couple of appeals if they don't use these mixture of electronic structures.

[16] noticeable that the effort of a company in making consistent \& strong associations for trade specific assets. Accordingly, firms keeps more reasonability of such Pleasant relationship. Thusly, supplier interest in particular exchange resources serves to abatement generation expenses \& builds creation productivity, serving to construct a superior agreeable relationship in the middle of suppliers \& purchasers.

Then, the purchaser has the expanded expense of exchanging trade of accomplices. Likewise, the suppliers that are needs to secure a helpful electronic inventory network association with an engine organization put resources into exchange particular resources, in agreeability with the significant resources, HR \& creation methodology of the purchaser. The above thinking demonstrates that supplier interest in important resources of generation techniques, in accordance with interest for electronic production network frameworks, help suppliers to create a long haul stable relationship; this can help to meet desires \& helpful relationship, with the purchaser.

[17] distinguished efficiency had confronted a few troubles, in light of the fact that diverse destinations of distinctive circumstances are the principle issue. The goals of firms $\&$ country can be diverse. The principle destinations of a country are to enhance the native's expectation for everyday comforts \& make more work. While the target of a firm is to augment benefit \& pieces of the pie both locally \& universally. Essential procedures are not used to quantify efficiency; rather nonstandard devices are being utilized to gauge \& assess profitability. The essential idea of efficiency is regularly misjudged. A primary downside of nonstandard apparatuses is that, they are not considering the time element. While in benefit procuring action time element is essential in characterizing when accomplished its wanted yield or when an administration arrangement rendered its adequacy.

The globalization of economies had made profitability an essential achievement variable for any nation on the planet. Most nations have made techniques \& strategies by reckoning these advancements to guarantee that their neighborhood organizations have the ability to contend in the worldwide business [18] sight a relationship as an open structure. An affiliation should relate with the outside environment to get the advantages for keep up legitimate survival.

[16] noticeable firms were willing to keep up the more reasonability of such Pleasant relationship, non-appearance, efficiency, turnover \& Word related anxiety. The most genuine test facing administration has been recognized as Efficiency. With the evolving time, more intensive examination \&studies are needed for measuring profitability \& notwithstanding characterizing efficiency. In the past couple of decades various investigation studies have been driven all over all through the world on effectiveness.

Pakistan came to a degree later than others into the race of productivity change; for example Gainfulness Relationship of Pakistan was dispatched on 25 April 2009, in Islamabad. Some change showed by the auto business of Pakistan generally as a result of updated capital inputs, yet its dedication to the Total national output is low \& vocation is of humble size. The other Asian countries like Japan, Malaysia, Korea, China \& Thailand a tremendous difference can be viewed. The auto business has basic part in progressing extensive based collecting section advancement in these countries [19]. In Pakistan, no investigation has been finished on the operational approach \& to change of gainfulness of the auto business.

[20] clarified that the headway in innovation had given a novel way to lead business \& these innovative changes have influenced each business methodology \& movement, including acquirement. E-business \& Internet have upset among the innovative headway, 
the way associations deal with their business forms. Electronic business incorporates robotiazation of business exchange through information transfers \& PCs. Some regular etrade advances are electronic mail, electronic announcement sheets, electronic stores exchange, electronic information exchange, brilliant cards, credits cards, web business \& eindexes.

Today, e-business is not a game changer but rather considered as important part for survival \& development in the worldwide markets. Pakistan is a huge business for autos $\&$ offers enormous business \& venture opportunities. The automobile parts industry has all things considered formed into all around sorted out part of the nation. Pakistan Car Industry has extensive works under the establishment \& specialized coordinated effort of Japanese, European, Chinese \& Korean automakers. Numerous enormous monsters \& quantities of sellers have effectively embraced new data framework advances.

Pakistani automakers embrace data framework advances in diverse stages, then again, number of organizations are making a decent attempt to adjust their e-acquirement frameworks with key business procedures. Study in car industry of Pakistan give a chance to contribute in the teaching of learning \& discoveries helped chiefs to adjust their business systems e.g. production network administration, time based buying, downright quality administration \& hierarchical combination with e-obtainment hones.

Data innovation empowered associations to make long haul contact with real suppliers through big business asset arranging (ERP), e-acquisition, e-barters, entomb hierarchical frameworks, e-source application, fabricating asset arranging (MRP), Feasibility of these systems \& profitability stream from motivation behind source to usage inside \& transversely over stock system frameworks. The ascent of new development, obtaining is one of various diverse business practices that are directed through information advancement.

[21] saw electronic sourcing is a procedure of distinguishing new suppliers for a particular classification, utilizing web innovation. E-sourcing is an "online administration that helps associations to deal with their sourcing over the procedure cycle online".

The most complete definition has been made by the Aberdeen gathering characterizing e- sourcing as "the utilization of online applications, choice bolster devices \& related administrations to distinguish, assess, arrange \& design buys \& supplier connections that viably bolster production network \& different business operations" [22,23]. E-sourcing is an electronic system that works through web \& empowered site or an e-commercial center which permits purchaser to explore data $\&$ in view of that data, recognize, assess arrange, $\&$ design their buys.

\section{Research methods}

Information is gathered through the auxiliary sources. The sources were Pakistan Auto Motive association (PAMA). Information of most recent 15 years was accessible for examination. Yearly information incorporates diverse sort of autos Honda Deal contains offers of Honda Urban, Honda City, Suzuki Deals incorporate Offers of Offers of Suzuki Baleno, Suzuki Liana, Suzuki Quick, Suzuki Cultus, Suzuki Aulto\& Suzuki Mehran. Sals of Kia incorporate Kia Fantastic \&Kia Spectra. Offers of Toyota Corolla, Nissan Sunny, HyundaiSantro\& Daihatsu Cuore are likewise included.

Annual sales of all mentioned automotive brands were gathered through auxiliary sources (Eikon) for 15 years beginning from 2000 to 2019. 


\section{Results}

From the annual sales of all outlined automotive brands the market shares was calculated while using the operation definition of market share. Finding confirms that in Pakistan in automotive or automobile, the Suzuki brand is enjoying the most market share among the outlined brands and leading the list with $29 \%$ of market shares. Toyota is enjoying $26 \%$ market shares while Honda brand is the third most winning brands in automotive industry in Pakistan with 25\% market shares. Further, Nissan, Kia and Daihatsu have 10\%, 6\% and $4 \%$ market shares respectively in automotive industry of Pakistan for the years 2000 to 2019.

Table 1. Value of markets shares by car brands in Pakistan, 2019.

\begin{tabular}{|c|c|}
\hline Automotive Brands in Pakistan & \% Mean Value of Market Shares \\
\hline Suzuki & 0.29 \\
\hline Toyota & 0.26 \\
\hline Honda & 0.25 \\
\hline Nissan & 0.10 \\
\hline Kia & 0.60 \\
\hline Daihatsu & 0.40 \\
\hline
\end{tabular}

\section{Discussions and conclusion}

In the innovative world Auto Industry is getting more significance with the section of time. [1] says that Globalization \& Innovation changes the car showcase drastically.

This is the most alluring approach to capture the consideration of the focused on gathering of people. Other than that strong commercial is likewise turned into the focal point of talk with respect to social sensitivity which makes negative effect on social qualities \& standards. This theory helps advertisers to which variable needs to concentrate in ad to market the item to maintain a strategic distance from the social clashes. The finding of the study discovered a noteworthy association with prohibitive disposition $\&$ age.

As per [10] numerous organizations are always enhancing the quality. On the off chance that the organization won't keep up the quality it bring about client disappointment \& inevitably lose piece of the pie \& give opponent opportunity to catch his offer.

Pakistan is much behind in innovative advancement in car area. [19] discovered the Pakistan car industry investment in Gross domestic product is still behind then other created nations.

It was found in this study that the Suzuki has the Biggest Share in Car industry of Pakistan. Suzuki's Generation \& Deals are higher than all others marks \& absolutely noteworthy from others. The outcome demonstrates that the Toyota is at number two \& its Deals \& preparations are all the more than a large portion of Suzuki's.

Honda holds third position in the business sector. These three brands appreciate greatest offer of business \& these can be said the pioneer of Pakistan Auto Industry. After these Nisan, Kia \& Daihatsu have separate partake in business sector.

In developing countries like Pakistan individuals have relatively lower wages, thus a vehicle-purchase decision requires more due-diligence, whereby the accessibility of carparts in neighborhood markets, how pricy the car parts are, \& the resale estimation of brand, are the primary decision-marking factors.

The highest market shares which is being enjoyed by Suzuki brand confirms that people of Pakistan buy Suzuki brand mostly due to the above mentioned factors. Therefore automotive businesses need not only focus upon bringing vehicles into the Pakistani 
market, but also need to focus upon rating high in the purchase decision-making factors as that of car-parts availability, credit/installment payments, and a worth-while resale price

\section{References}

1. Z. Altinkaya, Market Structure \& Globalization At Asian Countries With Specific Example Of Auto Industry In Pakistan, Far East Journal of Psychology \& Business 13(2), 10-23 (2013)

2. R. Khan, Failure of Automobile Manufacturing in Pakistan - A Case of the RevoCar. Interdisciplinary Journal of Contemporary Research in Business 4,4 (2012)

3. H.T. Van. et al. Liberal reforms \& economic growth: Current issues and interrelations. Journal of International Studies 10(4), 109-118 (2017)

4. M. Př́varová, A. Přívara, Migration policy of Slovak Republic: issues and challenges. Actual Problems of Economics 10, 324-331 (2015)

5. D. McFadden, Conditional log it analysis of qualitative choice behavior (1973)

6. M.A. McCollough, et al. An empirical investigation of customer satisfaction after service failure \& recovery. Journal of service research 3(2), 121-137 (2000)

7. S.Berry, et al.: Automobile prices in market equilibrium. Econometrica: Journal of the Econometric Society 841-890 (1995)

8. D. Ushakov. et al.: Post industrialization prospects in the dynamics of socioeconomic transformations: Cluster approach. International Journal of Ecological Economics and Statistics 38(2), 23-32 (2017)

9. I.N. Eugenia, Quality Improvement in a Global Competitive Marketplace-Success Story from Nigeria. International journal of business \& management 5(1), 211 (2009)

10. M. Pitukhina, et al. Environmental aspects of circular migration study impact on "back up zones" development in the Russian Arctic macroregion. International Journal of Ecology \& Development 32,3, 45-52 (2017)

11. D. Ushakov. et al.: Tax instruments in public regulation of population employment: The factors of today's efficiency. International Journal of Ecological Economics and Statistics 38(2), 161-168 (2017)

12. S.Z. Sarwar. et al.: Barriers of Productivity in Public Sector, World Academy of Science, Engineering \& Technology (WASET), Tokyo, 1222-1226 (2010)

13. V. Kumar, et al.: Impact of TQM on company's performance. International journal of quality \& reliability management 26(1), 23-37 (2009)

14. K. Phusavat, et al.: Performance measurement: roles \& challenges. Industrial Management \& Data Systems 109(5), 646-664 (2009)

15. X. Zhao, et al.: The impact of information sharing \& ordering co-ordination on supply chain performance. Supply Chain Management: an international journal 7(1), 24-40 (2002)

16. A. Zaheer, N. Venkatraman, Relational governance as an interorganizational strategy: An empirical test of the role of trust in economic exchange. Strategic management journal 16(5), 373-392 (1995)

17. D.J. Sumanth, Productivity engineering \& management: Productivity measurement, evaluation, planning, \& improvement in manufacturing \& service organizations. New York, NY: McGraw-Hill (1984) 
18. J. Pfeffer, G. Salancik, The external control of organizations: A resource dependence perspective. Stanford University Press (2003)

19. Asian Development Bank. Private Sector Assessment, Pakistan, Asian Development Bank Report, Asian Development Bank, Manila, December (2008)

20. M.N. Abbasi, M. Afzal, Impact of e- management, application on key business strategies - evidences from automotive industry of Pakistan. Journal of Quality \& Technology (2011)

21. G. Kozlov, M. Pushkarev, E3S Web of Conferences, 135, 01053 (2019) doi: $10.1051 / \mathrm{e} 3 \mathrm{sconf} / 201913501053$

22. T.Minahan, Strategic e-Sourcing: A Framework for Negotiating Competitive Advantage (2001)

23. A. Přívara, Labor market efficiency and emigration in Slovakia and EU neighboring countries. Economic Research-Ekonomska Istraživanja 33,1, 3307-3333 (2020) 